\title{
Parafusos, relógios e cartomantes: gênero e representação em A hora da estrela, de Clarice Lispector
}

Rebecca Pedroso Monteiro

Facisa-BH

\begin{abstract}
RESUMO
Análise do livro A hora da estrela (1977), de Clarice Lispector, a partir da comparação entre algumas das personagens do romance, cuja resistência à determinação pode ser vista como uma alegoria da falibilidade de toda representação e, portanto, um convite à revisão permanente dos juízos que compõem os estudos de gênero.
\end{abstract}

\section{PALAVRAS-CHAVE}

Clarice Lispector, personagens, representação, identidade, gênero

Ao nos aproximarmos de um livro como A hora da estrela (1977), a primeira coisa que se faz notar é seguramente a decisão clariceana de trabalhar com aspectos menos abordados em seus romances anteriores, mais precisamente aqueles relacionados a questões socioeconômicas, já que as personagens pertencem às camadas mais pobres da sociedade e lidam diariamente com a carência de recursos, com a exclusão social e com a falta de perspectivas. Essa escolha temática foi interpretada inclusive como uma espécie de resposta da autora às patrulhas ideológicas da década de 1970, que acusavam Clarice de ser alienada e de não procurar retratar o quadro político e social em que vivia, além de escrever livros herméticos que as massas não compreendiam. ${ }^{1}$

No entanto, por mais que isso possa ter sua carga de verdade, esse livro de Clarice não deve ser visto como o único livro "engajado" da autora, ou como uma obra menor, dado que menos livre, sujeita às pressões do contexto histórico da autora. Como alguns críticos perceberam, Clarice não se preocupou somente em trabalhar nessa obra com um conteúdo de

\footnotetext{
${ }^{1}$ Cf. PAGANINI. O engajamento poético: linguagem e resistência - A hora da estrela, de Clarice Lispector, e a literatura engajada brasileira pós-64, p. 5.
} 
conotação política e social, mas incorporou “a tensão política à sua própria linguagem”,2 questionando os moldes narrativos tradicionais e “duvidando da capacidade de sua própria escritura em apreender o real”. 3

Ainda que se possa admitir que as questões socioculturais apareçam na obra clariceana de maneira pouco óbvia ou conclusiva, não resta dúvida de que a insistência clariceana em falar sobre a dificuldade/impossibilidade de expressão e de representação do universo complexo e contraditório dos conflitos humanos pode ser tão (ou até mais) produtiva em termos de “crítica social” quanto decidir falar "pelos” marginalizados, tomando-os como dóceis corpos da diferença, ${ }^{4}$ como silenciados que desejam falar e não podem, como figuras subalternas, ${ }^{5}$ enfim, que precisam ser salvas de instâncias maiores ou mais poderosas do que elas.

Acostumamo-nos a pensar que o abismo que separa duas pessoas que pertencem a uma mesma classe é menor do que o que separa duas pessoas de classes diferentes. No entanto, ainda que isso possa ser verdade em alguns casos, certamente não o será para todos, já que o que conta para a superação (ou diminuição) desse abismo de "ignorância mútua” é o

\footnotetext{
${ }^{2}$ SUSSEKIND. Literatura e vida literária, p. 27.

${ }^{3}$ PAGANINI. O engajamento poético: linguagem e resistência - A hora da estrela, de Clarice Lispector, e a literatura engajada brasileira pós-64, p. 7.
}

${ }^{4}$ Cf. BHABHA. O local da cultura, p. 59.

${ }^{5}$ Usei aqui o termo "subalterno" para lembrar de um dos mais importantes textos de Spivak: Pode o Subalterno falar? Nesse artigo, a representação do discurso das camadas sociais excluídas do mercado e da cena política é finalmente posta como um problema para os intelectuais engajados, já que a fala do subalterno/excluído é sempre intermediada pela voz de outrem, que reivindica em seu nome, mas não o "deixa" falar. A cumplicidade bem-intencionada dos intelectuais é, portanto, ilusória e reprodutiva das estruturas de poder e opressão, já que mantém o silenciado sem voz, numa "mecânica da constituição do Outro", que, por fim, serve principalmente à constituição do Um como sujeito (Cf. SPIVAK. Pode o subalterno falar?, p. 81-84). Não é outro o problema para o narrador de A hora da estrela, que se vê sempre atravessado pela dificuldade de falar por Macabéa (e também sobre ela), sem imprimir na personagem seu próprio modo de ser ou de ver o mundo, e sem reprimir nela aquilo que ela é, ou pode ser. Como a linguagem usada pelo autor/narrador é muito diferente da linguagem da personagem, essas questões se multiplicam, e o próprio fato de sabermos que o narrador é "na verdade" Clarice Lispector torna ainda mais difícil e irônica a questão da representação do excluído, bem como o desejo/necessidade de representação desse excluído (que é, quase sempre, matizado por empenhos salvacionistas ou autoindulgentes, quando não declaradamente sectários).

${ }^{6}$ SANTIAGO. Uma literatura nos trópicos, p. 11. Refiro-me aqui ao momento em que Santiago observa como as "relações entre duas civilizações que são completamente estranhas uma a outra" acontecem a partir de uma "ignorância mútua", e não, como normalmente se pensa, a partir da ignorância do mais fraco, ou do chamado "selvagem" (Cf. SANTIAGO. Uma literatura nos trópicos, p. 9-17). 
que Silviano Santiago chamou de “desejo de conhecer”. ${ }^{7}$ Se esse desejo não existe, ou se ele é recalcado pela necessidade de eliminação/dominação por parte de um deles, certamente o que se produzirá serão figuras de emolduramento do outro, que, como Bhabha reconheceu, fazem como que esse Outro perca "seu poder de significar, de negar, de iniciar seu desejo histórico, de estabelecer seu próprio discurso institucional e oposicional”. 8

Se isso vale para o encontro entre culturas muito diversas, por que não valeria para encontros entre diferentes classes, gêneros, histórias de vida? Tentar medir o tamanho do abismo (social, racial, cultural, linguístico) que nos separa de Macabéa, ou de qualquer uma das figuras despaisadas que percorrem o livro, não é tão importante quanto reconhecer o “desejo de dominar”, violentamente atravessado pelo “desejo de conhecer”. De acordo com Homi Bhabha, o horizonte de esperança obrigatório para os que vivem no intervalo, para os corpos marginais dos que vivem "de outra forma que não a modernidade”, 9 não é o momento utópico de reencontro da essência, mas o encontro, em dissenso, de corpos que se enfrentam em agonia, buscando o próprio rosto. Cada um desses encontros traz em si a possibilidade (e a esperança) de nascimento de um novo sentido, o que é infinitamente rico e violentamente inóspito.

Lendo Clarice com o auxílio de Bhabha, percebemos que sua literatura também pode ser lida como uma forma de “encontro enfrentatório”, ou de colisão identitária, cujo horizonte de desejo pode ser entendido menos como uma forma de utopia do que como um desejo de solidariedade social. Um desejo que reconhece que a interioridade do sujeito é habitada por uma referência radical e anárquica ao outro. ${ }^{10} \mathrm{Ou}$, como Bhabha descreve, o "auto-amor que é também amor do outro: Eros e Ágape juntos.”11 Em A hora da estrela, os encontros e colisões identitárias acontecem o tempo todo, sempre exigindo do leitor um alto grau de participação, já que a orientação metaficcional e autorreflexiva do texto, sua "espontaneidade figurada", 12

\footnotetext{
${ }^{7}$ SANTIAGO. Uma literatura nos trópicos, p. 11.

${ }^{8}$ Cf. BHABHA. O local da cultura, p. 59.

${ }^{9}$ BHABHA. O local da cultura, p. 42.

${ }^{10}$ LEVINAS citado por BHABHA. O local da cultura, p. 40.

${ }^{11}$ BHABHA. O local da cultura, p. 40.

${ }^{12}$ De acordo com Carlos Mendes de Sousa, o livro A hora da estrela é o "exemplo mais acabado da orientação metaficcional” presente na obra clariceana (SOUSA. Clarice Lispector: figuras da escrita, p. 54.)
} 
cria a ilusão de que ele está sendo escrito no momento em que é lido, e que o leitor pode efetivamente participar no “desenrolar dos acontecimentos que a ficção vai lhe mostrando" 13

Um dos melhores exemplos desse tipo de encontro entre autores, personagens e leitores, está no final do livro, quando Macabéa, depois de ser violentamente atropelada ao sair da cartomante, encontra-se estendida na rua, oscilando entre a vida e a morte, lutando por alguma espécie de futuro.

Nos momentos que antecedem a "hora de estrela de cinema de Macabéa morrer”, o leitor é convidado a "rezar por ela”, a “interromper” o que está “fazendo para soprar-lhe vida”. ${ }^{14}$ Se o que se exige é que se "interrompa” o eu a fim de tentar alcançar o outro, a imagem do profundo beijo boca a boca ${ }^{15}$ torna-se destacável, porque expõe o grau de proximidade e o nível de comprometimento que o autor, Rodrigo S.M. (na verdade Clarice Lispector), pretende estimular. Ao doar o próprio alento, aproximamo-nos da morte de Macabéa, mas também da sua vida, ainda que essa vida nos seja muito incômoda, tanto por sua (falta de) dimensão social, quanto pela constelação de carências que articula.

Essa personagem sem lugar no mundo, “encardida”, “murrinhenta”, com “maus antecedentes" e de "corpo cariado", ${ }^{16}$ não permite espelhamentos simplistas do tipo "eu sou como ela”, ou “eu tenho o que ela não tem”. Macabéa é “um acaso”; é “crônica”; é “um cabelo na sopa”; um “café frio”. ${ }^{17}$ Ela não nos pode entregar nada, pois pouco tem. No entanto, é para esse excesso de vazios que o leitor é convocado; é essa vida lacunar que se espera que ele ajude a fazer viver; é essa boca feia e fria que se espera que ele beije. O que se exige do leitor (bem como do próprio autor/narrador), portanto, é uma entrega limite, radical. O que se exige é a extrema doação de vida, a despeito da profunda carência da personagem, das carências do próprio leitor e da impossibilidade mesma de qualquer encontro.

Mas o encontro se faz, mesmo assim: "Macabéa me matou. Ela estava enfim livre de si e de nós. Não vos assusteis, morrer é um instante, passa logo, eu sei por que acabo de morrer com a moça.” ${ }^{18}$ Essa morte conjunta, depois de oito páginas de expectativa, pode ser lida como uma espécie de ponte efêmera entre ambos (e entre eles e nós, leitores). Diante do mais terrível dos encontros, todos nós falhamos. Tentamos amá-la, tentamos salvá-la, e não

\footnotetext{
${ }^{13}$ SOUSA. Clarice Lispector: figuras da escrita, p. 347.

${ }^{14}$ LISPECTOR. A hora da estrela, p. 102.

${ }^{15}$ Cf. LISPECTOR. A hora da estrela, p. 102.

${ }^{16}$ LISPECTOR. A hora da estrela, p. 84, 42 e 51.

${ }^{17}$ LISPECTOR. A hora da estrela, p. 52, 79, 78 e 42.

${ }^{18}$ Cf. LISPECTOR. A hora da estrela, p. 105.
} 
conseguimos. Ou não nos atrevemos a dar a ela nosso alento (ou nosso amor), e a matamos. Impotência ou covardia, é isso que temos nas mãos. Dois limites, bastante radicais, que a escrita de Clarice nos obriga a encarar. No entanto, se uma fronteira é “o ponto a partir do qual algo começa a se fazer presente”, 19 o que esse violento encontro com o (não) amor, a falência e a morte pode nos trazer além de desespero?

A escrita clariceana, ao nos conduzir aos "limites do ser e da existência”, em que a “intensidade da entrega pressupõe a inclusão da figura do eu (o trabalho sobre si mesmo) no processo de pesquisa que é a escrita” ${ }^{20}$, abre-se para um vazio que é pura potência. Só aqui, sem nada nas mãos, podemos (desejar) ser alguma coisa diferente do que nos acostumamos a ser, e que só esse vazio mostra como é insuficiente. O desejo de respirar só acontece quando o ar nos falta? Talvez seja preciso sempre morrer, para se fazer outro.

Mas quem sabe se ela não estaria precisando de morrer? Pois há momentos em que a pessoa está precisando de uma pequena mortezinha e sem nem ao menos saber. Quanto a mim, substituo o ato da morte por um seu símbolo (...). Eu que simbolicamente morro várias vezes só para experimentar a ressurreição. ${ }^{21}$

O encontro com a presença radicalmente lacunar de Macabéa apresenta-se como abertura possível para o encontro com outras formas possíveis de ser e de encarar a diferença, o amor, a solidariedade e a morte. No entanto, muitos outros encontros e colisões identitárias são articulados entre os diferentes elementos lacunares dessa obra clariceana, permitindo que nossas formas habituais de pensar o mundo, e o mundo dos outros, sejam (pelo menos) colocadas sob suspeita. No campo específico do gênero, acreditamos que a resistência dessas personagens aos modos habituais de representação podem ser encaradas como uma alegoria da falibilidade de toda representação e, portanto, um convite à revisão permanente dos juízos que compõem (ou podem vir a compor) esse campo de estudos.

Olímpico, Glória e a cartomante são figuras “representativas” de sua classe e gênero, mas, ao mesmo tempo, essa representatividade é ironicamente exposta e demolida, o tempo todo, por sua banalidade, vulgaridade e insuficiência. É como se eles fossem tão óbvios e comuns que nos afetassem diretamente, porque sua vida é também a nossa, ao mesmo tempo que não é: muito iguais por serem diferentes, e muito diferentes por serem iguais. Essa plasticidade relativa (ou reativa) é bastante incômoda, o que é comum na obra clariceana, mas

\footnotetext{
${ }^{19}$ HEIDEGGER, citado por BHABHA. O local da cultura, p. 19.

${ }^{20}$ SOUSA. Clarice Lispector: figuras da escrita, p. 37 e 30.

${ }^{21}$ LISPECTOR. A hora da estrela, p. 102.
} 
é também um modo de fazer colidir, no plano da literatura, o que desejamos (personagens comuns, ou incomuns) com o que encontramos (personagens invulgares, ou vulgares), sem nunca nos deixar satisfeitos, e sem nunca deixar de nos obrigar a perguntar "quem [afinal] sou eu?”. Mas, esse “quem sou eu? provoca necessidade. E como satisfazer a necessidade? Quem se indaga é incompleto."22

Olímpico de Jesus, por exemplo, era "homem com letra maiúscula”, porque havia matado um desafeto nos “cafundós do sertão”. Fazia segredo disso, o que fazia dele um “macho de briga”, um “cabra safado”, cuja "resistência provinha da paixão por sua terra braba e rachada pela seca”. Apesar dessa "força de vida”, que lhe tirava a inocência, mesmo sendo "uma vítima geral do mundo", e apesar de gostar de se vingar e de roubar "sempre que podia”, Olímpico “fraquejava em relação a enterros”, e ia três vezes por semana a enterros de desconhecidos, quando se permitia chorar.

De acordo com o autor, “ter matado e roubar faziam com que ele não fosse um simples acontecido qualquer, davam-lhe uma categoria, faziam dele um homem com honra já lavada”. Esse nordestino “brabo”, oposto em tudo à “figura medieval” de Macabéa, louco por sangue e por touradas, acumula, por assim dizer, os clichês reservados aos personagens "bandidos” das narrativas novelescas populares, trazendo “dentro de si a dura semente do mal”. Mas é justamente esse acúmulo, acrescido de expressões ambíguas (“pelo menos roubava”) ou sarcásticas ("se era doido, sabia muito bem o que queria. De modo que não era doido coisa alguma”), que faz desse “frágil machinho” uma figura literária bastante caricatural, inclusive em seus momentos de fraqueza ou suavidade, ao esculpir figuras de santo nas horas vagas, ao chorar em enterros ou ao ter "fome de ser outro", porque no fundo "não passava de um coração solitário pulsando com dificuldade no espaço”. ${ }^{23}$

A banalidade de Olímpico é tão ostensiva quanto estranha, funcionando como um ajuste de contas ambivalente em relação ao aparato de estereótipos que nossa cultura reserva aos nordestinos. Seu próprio nome é uma espécie de irônica salvaguarda contra a mediocridade de seus "pensamentos”, de suas ações, de seu futuro como deputado. ${ }^{24}$ Seu nome, quase heroico para uma figura chinfrim (mas que se julgava “peça-chave” ${ }^{\text {”25 }}$ ), não deixa também de lançar uma luz de sarcasmo sobre o que ele pensa sobre as duas mulheres que

\footnotetext{
${ }^{22}$ LISPECTOR. A hora da estrela, p. 30.

${ }^{23}$ As citações referentes a Olímpico nesse parágrafo se encontram, respectivamente, em LISPECTOR. A hora da estrela, p. 74, 62, 74, 75, 62, 74, 64, 75, 63, 64, 75 e 83.

${ }^{24}$ LISPECTOR. A hora da estrela, p. 62 e 63.

${ }^{25}$ LISPECTOR. A hora da estrela, p. 63.
} 
namora, Macabéa e Glória. A primeira era “um cabelo na sopa”, “não [dava] vontade de comer”, só sabia falar bobagens e tinha "cara de quem comeu e não gostou”. ${ }^{26}$ A segunda, por outro lado, “apesar de feia, era bem alimentada”, e isso fazia dela “material de boa qualidade". ${ }^{27}$ Glória talvez desse uma "boa parideira", tinha mãe, pai açougueiro e comida quente na hora certa, além de ser carioca, o que "tornava-a pertencente ao ambicionado clã do sul do país”. ${ }^{28}$

A vulgaridade desses juízos, tão destacada pela ironia clariceana, escancara os ambivalentes processos que articulam as identidades e desejos sexuais, bem como sua estrutura simbólica. A figura feminina como objeto (material), disponível para o gozo (sexual ou estético) masculino e reduzida à procriação e alimentação dos filhos, encontra, na figura de Glória, sua mais expressiva representante e, na figura de Macabéa, sua mais singular falência. Ambas oferecem, pela voz de Olímpico, uma contraimagem grotesca para uma certa definição do feminino que não cansa de nos assombrar.

De um lado, temos a "parideira": a gorda branca que "tinha em si a força da mulatice”; “possuía no sangue um bom vinho português” e era "amaneirada no bamboleio do caminhar por causa do sangue africano escondido" - a mistura brasileira “clássica” era "um estardalhaço de existir”. ${ }^{29}$ De outro, temos Macabéa, cujo “corpo cariado” e magro tinha tanta lascívia que ela nem sabia que tinha. ${ }^{30}$

Glória é a caricatura da mulher pobre “que se dá valor”, cheia de corpo, de “traseiro alegre” e buço forte, oxigenado, “uma safadinha esperta mas [com] força de coração”. ${ }^{11}$ Já Macabéa é a alegoria das insuficiências do mundo. Incapaz de corresponder ou de se ajustar a qualquer um dos “tipos femininos” disponíveis no mercado, ela nos oferece um repositório de desejos em desordem, numa mistura caótica de elementos da cultura de massa que, no limite, a ajudavam a representar “com obediência o papel de ser”. ${ }^{32}$ Ao deus-dará, numa espécie de acaso, a história de Macabéa “sai como sair”, e chega mesmo a se assemelhar à sua própria coleção de anúncios recortados de jornais velhos - aleatória e estranha. ${ }^{33}$ Se Glória, gloriosa

\footnotetext{
${ }^{26}$ LISPECTOR. A hora da estrela, p. 78, 63 e 69.

${ }^{27}$ LISPECTOR. A hora da estrela, p. 77.

${ }^{28}$ LISPECTOR. A hora da estrela, p. 77 e 76.

${ }^{29}$ LISPECTOR. A hora da estrela, p. 76 e 78.

${ }^{30}$ LISPECTOR. A hora da estrela, p. 78.

${ }^{31}$ LISPECTOR. A hora da estrela, p. 82.

${ }^{32}$ LISPECTOR. A hora da estrela, p. 52.

${ }^{33}$ LISPECTOR. A hora da estrela, p. 52 e 54.
} 
de ser, nos oferece algo que costumamos reconhecer como parte do universo feminino, por mais vulgar que pareça, Macabéa não nos oferece senão nuances esquivas de uma sociedade embotada e adormecida sob o seu arsenal de símbolos: cremes, batons rosas e vermelhos, cartomantes, aspirinas, coca-cola, cultura em gotas, pregos e parafusos, açougues, relógios de pulso, chocolate, psicanalistas, sabão aristolino, novidades clínicas e eletrônicas, descolorantes, cerveja, Jesus, Mercedes amarelas e "noivas flutuando em branco”. ${ }^{34}$

Como Olímpico e Glória, Macabéa também é uma caricatura, porém falida. Sua figura é arredia, esquiva, incapaz de se encontrar ou de se assemelhar a nada, impossível de reconhecer ou de observar sem o auxílio dos “pregos e parafusos” simbólicos que aparelham a máquina do mercado de consumo. Sua figura é estranha e familiar ${ }^{35}$ ao mesmo tempo, e serve como contraponto mordaz às imagens excessivamente brilhantes de Olímpico e Glória. Apesar de tudo o que lhe falta, Macabéa é uma mulher. Seu "sexo miúdo mas inesperadamente coberto de grossos e abundantes pêlos negros - seu sexo era a única marca veemente de sua existência.”36 Essa imagem realista, lançada em meio ao caledoscópio de clichês de gênero, torna quase ridículas, tanto a masculinidade performática de Olímpico quanto a feminilidade astuta de Glória.

A partir desse triângulo amoroso nem tão banal, formado por duas caricaturas e uma contracaricatura, toda uma série de atritos simbólicos relacionados às questões de gênero parece ser ativada. A partir das figuras confiantes de Glória e Olímpico e da figura trêmula e oblíqua de Macabéa, identificações, sobreposições e agenciamentos simbólicos de variadas ordens podem ser colocados sob suspeita. Enquanto lemos, e nos capturamos na contraidentificação (“eu não sou como eles”), o próprio autor (na verdade Clarice Lispector) nos oferece o contraponto da dúvida: “Quando penso que eu podia ter nascido ela - e por que não? - estremeço. E parece-me covarde fuga o fato de eu não a ser, sinto culpa.”37

Essa pergunta - e por que não? - abre caminho para muitas outras, atravessadas pela mesma impotência e pela mesma covardia que sobrevoam a cena final da morte de Macabéa: nosso alento não pode salvá-la; nossa omissão se recusa a fazê-lo.

O abismo (entre nós e eles) torna-se, a partir dessa pergunta, menos instransponível: afinal, também nós não somos vulgares representantes do nosso gênero? Também nós não

\footnotetext{
${ }^{34}$ LISPECTOR. A hora da estrela, p. 58.

${ }^{35}$ Cf. FREUD, O estranho, p. 283: "Heimlich é uma palavra cujo significado se desenvolve na direção da ambivalência, até que finalmente coincide com o seu oposto, Unheimlich”.

${ }^{36}$ LISPECTOR. A hora da estrela, p. 88.

${ }^{37}$ LISPECTOR. A hora da estrela, p. 54.
} 
descolorimos os pêlos, ou choramos em enterros, ou nos sentimos perdidos, ou queremos matar e roubar, e nos vingar, e amamos anúncios, e tomamos aspiranas, e sorvemos pílulas de cultura para nos encaixar na máquina banal da modernidade? Também nós não somos meros parafusos, correndo atrás do que mandam os relógios, tão vazios e adormecidos que só temos como esperança o que nos predizem as cartomantes? Também nós não sabemos conviver com a questão de Macabéa: quanto ao futuro (assim mesmo, sem a interrogação, e entre dois pontos finais). ${ }^{38} \mathrm{O}$ futuro pode ser (explosão) tão insuficiente quanto o presente. Tão falido quanto. Vivemos de seus enganos.

O futuro de homens e mulheres, peças substituíveis no maquinário sofisticado da sociedade pós-industrial, só pode ser revisado, ou transformado, na potência do presente. Isso sabemos, mas saber disso não é suficiente. Clarice nos lembra, irônica, no fim de sua narrativa, que "por enquanto é tempo de morangos", 39 o que nos devolve rapidamente, não sem algum amargor, à sociedade de consumo e a seus prazeres infindáveis. "Viver é luxo.”40 Macabéa está morta, outras como ela virão e morrerão, mas por enquanto tudo está bem, podemos nos divertir com os morangos. No entanto, o travo amargo de Macabéa parece ecoar: “eu sou, eu sou, eu sou." ${ }^{41}$ Mais e menos do que uma mulher, ela é. Mais e menos do que um homem. Ela é. Ela foi. Nós somos. Crônicos. Insuficientes.

Se é assim, Macabéa não pode ser vista como uma contínua insuficiência (uma entre outras)? E a insuficiência que é a dela não nos convoca, sem retorno, para as nossas? Se essa convocação for suficiente para mudarmos o mundo, bem. Mas se não for, caímos de novo no impasse, duramente covardes e impotentes, o que não deixa de funcionar como mais uma das ironias clariceanas que povoam esse romance-paródia. De novo e de novo, Clarice nos lança no vazio. No nosso e no alheio. No entanto, assim como no encontro com a morte de Macabéa, só esse vazio nos oferece a possibilidade do salto transformador: "ela nada pedia, mas seu sexo exigia, como um nascido girassol num túmulo.”42

Exigia o quê? Pode-se perguntar. Apenas exigia, pode-se responder. Exigia como recurso último do corpo da diferença, exigia por exigir, para não morrer de todo, para continuar incomodando. Sim.

\footnotetext{
${ }^{38}$ LISPECTOR. A hora da estrela, p. 104.

${ }^{39}$ LISPECTOR. A hora da estrela, p. 106.

${ }^{40}$ LISPECTOR. A hora da estrela, p. 105.

${ }^{41}$ LISPECTOR. A hora da estrela, p. 103.

${ }^{42}$ LISPECTOR. A hora da estrela, p. 88.
} 


\begin{abstract}
This paper presents an analysis of Clarice Lispector's novel A hora da estrela (1977), discussing the novel's characters whose resistance to determination can be seen as an allegory of the fallibility of all representation and, because of that, it can also be seen as an invitation to the permanent revision of judgment which informs the studies of gender.
\end{abstract}

KEYWORDS

Clarice Lispector, characters, representation, identity, gender

\title{
REFERÊNCIAS
}

BHABHA, Homi K. O local da cultura. Trad. Myriam Ávila, Eliana Lourenço de Lima Reis, Gláucia Gonçalves. Belo Horizonte: Editora UFMG, 1998.

FREUD, Sigmund. O estranho. In: Obras psicológicas completas. Volume XVII: Uma neurose infantil e outros trabalhos (1917-1919). Trad. Jayme Salomão. Rio de Janeiro: Imago, 1976(b). p. 275-315.

LISPECTOR, Clarice (1977). A hora da estrela. Rio de Janeiro: Francisco Alves, 1992.

PAGANINI, Joseana Geaquinto. O engajamento poético: linguagem e resistência - A hora da estrela, de Clarice Lispector, e a literatura engajada brasileira pós-64 (Mestrado em teoria Literária). Brasília, UNB, 2000.

SANTIAGO, Silviano. Vale quanto pesa; ensaios sobre questões político culturais. Rio de Janeiro: Paz e Terra, 1982.

SANTIAGO, Silviano. Uma literatura nos trópicos: ensaios sobre dependência cultural. Rio de Janeiro: Rocco, 2000.

SOUSA, Carlos Mendes de. Clarice Lispector: figuras da escrita. Braga: Universidade do Minho/Centro de Estudos Humanísticos, 2000.

SPIVAK, Gayatri. Pode o subalterno falar? Trad. Sandra Regina Goulart Almeida, Marcos Pereira Feitosa e André Pereira Feitosa. Belo Horizonte: Editora UFMG, 2010.

SUSSEKIND, Flora. Literatura e vida literária. Rio de Janeiro: Jorge Zahar, 1985. 